\title{
RISK-BASED CONTROL OF THE NEGATIVE EFFECT OF DISCONTINUED AUTOMATED PROCESSES - A CASE FROM THE AGRICULTURAL DOMAIN
}

\section{Athanasios Podaras}

\section{Introduction}

The emergence of ICT technologies in the modern era has facilitated and ameliorated the execution of critical business processes. Agriculture is a domain where automation is present in various forms, important and enables farmers increase productivity and improve environmental policies. However, the "industries are faced with numerous types of natural and man-made threats and disruptions" (Maboudian \& Rezaie, 2017). As a consequence, effective policies against such threats should be developed.

Business Continuity Management (BCM) is a process that allows to efficiently overcome operational disruption whereas the organization should be prepared for an emergency situation e.g. accident to be able to minimize its impact and enable the fastest recovery possible (Malachová \& Oulehlová, 2016). Additionally, risk management is a crucial element for understanding the organization in order to implement an integrated business continuity management strategy (ISO 22301, 2012). "Risks are part of every business operation and can never be avoided completely. To minimize the danger of corporate crisis, a conscientious and responsible approach to the handling of risks and the resulting impact on business is essential. Unforeseen events pose an especially great challenge for companies and require quick decision-making and immediate reactions" (Breuer et al., 2015).

Agriculture is a domain where the incorporation of an integrated business continuity management system is a crucial issue. In the agricultural sector "the preservation of processes is not dependent solely on information systems, but on the continuity of all processes that lead to the fulfilment of the global goal of agriculture" (Hajek \& Urbancova, 2013). Moreover, agricultural business is highly exposed to natural hazards. This has been proved by multiple recent facts and studies. A representative study (Okuda et al., 2011) delineates the major impact of an earthquake in East Japan on different agricultural sectors, especially farming and fishery. The early detection and management of risks is an integral part of the strategic management for agricultural organizations (Jankelova et al., 2017).

"Risk management in agriculture is now an essential tool for farmers to anticipate, avoid and react to shocks. An efficient risk management system for agriculture will preserve the standard of living of those who depend on farming, strengthen the viability of farm businesses, and provide an environment which supports investment in the farming sector (OECD, 2011). Risk management is an essential part of an integrated strategy regarding the estimation of the impact of various humanly and technically triggered hazards on the environment (Aukidy et al., 2014).

On the other hand, natural hazards also threaten the continuous and normal operations of critical information systems and business functions. Resumption of critical processes/ functions after the occurrence of any disruptive event is essential from the business continuity (BC) viewpoint (Torabi et al., 2014). It is, thus, important to develop strategies which can predict the maximum accepted resumption timeframes of the interrupted critical activities when a crisis occurs.

Resumption timeframes can be determined after the implementation of business continuity tests. Regular testing increases the ability of employees to respond flexibly to unexpected events (Malachová \& Oulehlová, 2016). The official maximum time during which a business process should be recovered is known as Maximum Tolerable Period of Disruption 
(MTPD) or Maximum Tolerable Downtime (NIST, 2010; Harris, 2010; Torabi, 2014). Additionally, due to the fact that critical business operations should ideally recovered before this maximum tolerable downtime period, a Rational Time Objective (RTO) (ISO 22301, 2012; NIST 2010) should be considered as the target recovery time for business functions and information systems. Furthermore, the minimum accepted level regarding the operation of a business function, namely Minimum Business Continuity Objective (MBCO) (Torabi, 2016) should be achieved within the desired MTPD.

The goal of the current paper is the introduction of a semi-quantitative risk management algorithmic procedure for the determination of both the RTO as well as the Maximum Tolerable Downtime (MTD) resumption timeframes, based on the assumption that during the recovery process various environmental hazards can significantly extend the duration of the interruption of an individual business function. The overall risk magnitude of all potential factors is utilized for estimating the time deviation from the recovery timeframes proposed in ideal conditions. The algorithm's evaluation is implemented via the formula which estimates the availability of a system. Availability is defined as the "probability that an item will perform its required function under given conditions at a stated instant of time" (Garcia et al., 2016). The approach is then validated via the information system availability formula by replacing the Mean Time To Repair (MTTR) variable with the new estimated recovery time. The acceptable availability percentage must be greater than or equal to $99 \%$. The approach is further validated via an agricultural case study, namely the irrigation management system in greenhouses. The specific algorithm has interdisciplinary value, yet, its application in the agricultural domain can be highly profitable due to its vulnerability in unforeseeable and hard to assess environmental hazards.

\section{Problem Statement and Motivation}

The relationship between the environmental conditions with the interruption of critical business activities is, in a sense, bidirectional. On one side, natural disasters and in general environmental hazards are among the factors which can severely impact productivity and growth (Faertes, 2015). Many crucial sectors of the global economy such as the industry (Maboudian \& Rezaie, 2017) and agriculture (Okuda et al., 2011) as well as their core ICT dependent business functions are highly exposed to natural hazards. A recent study analyzes the risks and negative effects of severe weather conditions in agriculture (Stulec et al., 2016). Consequently, these sectors and especially agriculture are highly threatened by unexpected operational failures with a subsequent unpredictable financial impact.

On the other hand, since multiple crucial agricultural business activities are based on information technologies, a possible interruption of these information systems can have an immense impact on the environment. A representative example of such systems is the irrigation systems. For example, in Spain a high percentage of farms have programmable irrigation automata which allow farmers control effectively irrigation parameters (Contreras et al., 2017). It can be thus realized that even a temporary interruption of such systems can result to errors regarding the overall water management process, ranging from water overconsumption (Contreras et al., 2017) to nitrate pollution (Thompson et al., 2007).

The major challenge of the current research is the proposal of an algorithm which can efficiently mitigate the risk of prolonged information system failover in the agricultural sector and prevent, to the fullest possible extent, similar to the above mentioned negative environmental consequences. Risk assessment methodologies are considered to be powerful tools for supporting Business Continuity Plans (Faertes, 2015). Especially, semi-quantitative risk assessment has multiple advantages comparing to the qualitative as well as the quantitative techniques. The former is not consistent enough while the latter requires not only strong mathematical skills but, additionally, it cannot be applied if historical data is missing (FAO, 2009).

The proposed algorithm is based on the quantitative weight calculation for each unexpected factor that may emerge during the recovery process, which stems from the application of the Rank Order Centroid (Barron \& Barrett, 1989), a simple and widely utilized method for quantitative weight assignment and ranking (Danielson et al., 2015). Moreover, since the current approach is aimed for recovery scenarios where no past data is at the disposal of domain 
or business continuity experts, the estimation of the probability of occurrence of each factor is based on their semi-quantitative opinion. Domain experts are considered to be experienced farmers or agronomists. The approach permits a 1-5 scale for probability evaluation.

\section{Material and Methods}

\subsection{Proposed Business Continuity Resumption Timeframes}

Typical proposed recovery timeframes for any interrupted business function (BF) by business continuity experts are the following (Harris, 2010):

- BF Extremely Critical: MTD=24 Hours and RTO $<24$ Hours.

- BF Very Highly Critical: $M T D=3$ Days and 1Day $<$ RTO $<=3$ Days.

- BF Highly Critical: $M T D=1$ Week and 3 Days $<$ RTO $<=1$ Week.

- BF Important: MTD= 4 Weeks and 1 Week $<$ RTO $<4$ Weeks.

- BF Important but not Critical: $\mathrm{MTD}=$ 1 Month+ and RTO $<1$ Month.

\subsection{Risk Magnitude}

Risk is a part of life, with both its underestimation and overestimation having the potential for unfortunate consequences (Burns \& Slovic, 2012). The risk level is defined by the measurement of severity and likelihood (Borghesi \& Gaudenzi, 2013). Risk analysis frameworks with respect to an integrated business continuity management has been already proposed by academics, who indicate that $\mathrm{BCM}$ „enables the organizations to improve their resilience in order to cope with the identified risks" (Torabi et al., 2016). Nevertheless, no technique or similar framework has been proposed for utilizing risk magnitude in order to estimate the additional, from the initially defined by experts, recovery time effort required to recover an individual business function or information system, when a list of unexpected factors emerge during the recovery process.

The currently proposed framework is based on the idea that experts may estimate a recovery time effort for an individual business function according to its corresponding business continuity exercise without initially considering a set of possible unexpected events (factors) which can significantly delay the recovery process. It is thus reasonable to develop a technique which is able to estimate this additional recovery time required to recover a business function or an information system in these conditions. This additional required time is calculated based on the risk magnitude for a set of unexpected factors.

The derived by the author risk magnitude formula, which is based on the risk level definition provided by Borghesi and Gaudenzi (2013) estimates the overall magnitude for $\mathrm{N}$ number of unexpected factors and is provided by the following equation (Eq. 1):

$$
R M=\sum_{i=1}^{N} W_{i} P_{i}
$$

where $W_{i}$ and $P_{i}$ the weight and the probability of occurrence of the ith factor. The method of their calculation is the following:

The Weight Assignment of the considered factors is quantitatively estimated with the Rank Order Centroid Method (Barron \& Barrett, 1989) according to the following formula:

$$
W_{i}=\frac{1}{m} \sum_{i=1}^{m} \frac{1}{n}, \quad \text { and } \quad \sum_{i=1}^{m} W_{i}=1
$$

Tab. 1: The Semi-quantitative probability rating for unexpected factors

\begin{tabular}{l|c}
\multicolumn{1}{c|}{ Rating } & Probability Score \\
\hline Very Low & 1 \\
\hline Low & 2 \\
\hline Medium & 3 \\
\hline High & 4 \\
\hline Very High & 5 \\
\hline
\end{tabular}




\section{Informační management}

This formula (Eq. 2) prohibits the arbitrary weight assignment of the presence for a given factor during the BF Recovery process. The probability $\left(P_{i}\right)$ of occurrence of a specific factor is semi-quantitatively defined based on following a 1-5 scale (see Tab. 1).

\subsection{Availability of an Information System}

The availability is calculated according to the following formula (Eq. 3) (García et al., 2016):

$$
A=\frac{M T B F}{M T B F+M T T R}
$$

where $M T B F=$ Mean Time Between Failure, $M T T R=$ Mean Time to Repair, and $A=$ Availability of a system for a given time period.

The above formulas indicate that when the Availability value is known, and an acceptable number of possible failures is proposed by domain experts, then a Mean Time to Repair (recovery time) can be also estimated.

\subsection{Data}

a) Data based on the assumed unexpected factors:

The currently proposed algorithm is practically demonstrated via an agricultural case study. At first, 4 possible unexpected factors which can significantly delay the recovery of a greenhouse irrigation management system are considered. The assumed dataset is the following (see Tab. 2).

Moreover, the above estimated RM values are utilized as drivers to calculate the new recovery time effort. The validation of the approach is achieved by applying the derived recovery time to the system availability formula in order to estimate the availability rate for effective irrigation treatment.

b) Data regarding effective irrigation treatments:

During recent experiments that involved intensive irrigation treatment through drip irrigation system, the domain experts proposed that irrigation systems should be programmed to operate effectively as follows (Contreras et al., 2017): "The period of activation of irrigation was the same for all treatment and was 10:00 to $18: 00 \mathrm{~h}$ in winter and from 8:00 to $20: 00 \mathrm{~h}$ in the

\section{Tab. 2: The assumed dataset including 4 possible unexpected factors}

\begin{tabular}{l|c|c|c}
\multicolumn{1}{c|}{$\begin{array}{c}\text { Considered } \\
\text { Unexpected Factors }\end{array}$} & $\begin{array}{c}\text { Impact (Weight } \\
\text { Value) based on ROC } \\
\text { Method }\end{array}$ & $\begin{array}{c}\text { Probability } \\
\text { of Occurrence } \\
\text { (based on a 1-5 Scale }\end{array}$ & $\begin{array}{c}\text { Risk Magnitude } \\
\text { for Each Factor }\end{array}$ \\
\hline F1 (Flood) & 5.2 & 2 & 10.4 \\
\hline F2 (Severe Weather Conditions) & 2.7 & 5 & 13.5 \\
\hline F3 (Network Failure) & 1.5 & 2 & 3.0 \\
\hline F4 (Staff Unavailability) & 0.6 & 4 & 2.4 \\
\hline
\end{tabular}

Source: own

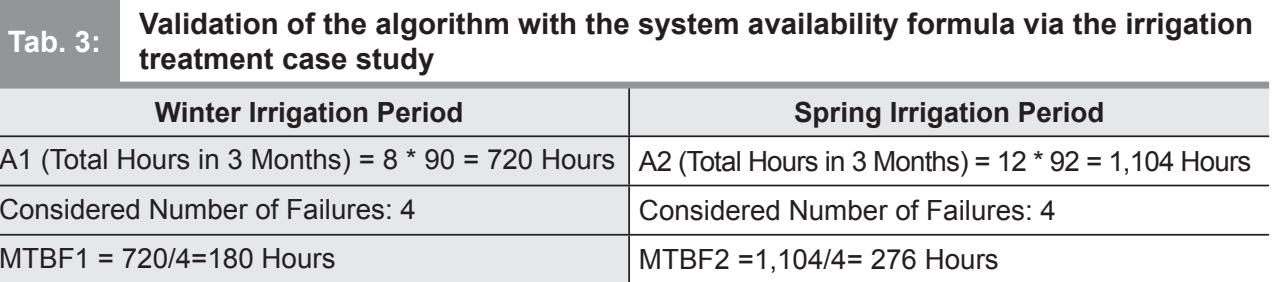


spring". Thus the following calculations can be derived (see Tab. 3).

\section{Results}

\subsection{Representation of the Algorithmic Risk Management Process}

The proposed contribution is formulated by combining semi-quantitative and quantitative techniques, and is aimed for assessing the risk of the significantly prolonged information system interruption. In the agricultural domain, some systems are executing highly critical activities including the control of gas emissions (Herbane, 2010) (i.e. in greenhouses), or those which are aimed for managing efficiently the water consumption (Wang \& Hu, 2012; Contreras et al., 2017). It can be, thus, realized that the proactive risk mitigation of such a threat is of major importance for multiple agricultural business functions.

The currently proposed framework includes the following algorithmic steps (see Fig. 1):
- Definition of the Estimated Recovery Time for an individual business function.

- Determination of whether the business function is included in the MBCO or not.

- Consideration of a number of factors which can have negative impact on the recovery procedure of the interrupted business function.

- Quantitative weight assignment for all the involved factors with the Rank Order Centroid method (ROC).

- Define semi-quantitative probability of occurrence for each factor.

- Estimation of the total risk magnitude for all factors with regard to the recovery process.

- Estimation of the absolute value of the time deviation from the initially estimated recovery time. The positive or negative value depends on the existence of the specific business function in the MBCO. The Time Deviation is the result of the product of the initial recovery time multiplied by the ratio total risk magnitude divided by 100 .

- Termination of the process.

\section{Fig. 1: The flowchart of the risk management algorithmic process for estimating the possible deviation from the initial recovery time effort (RTE)}

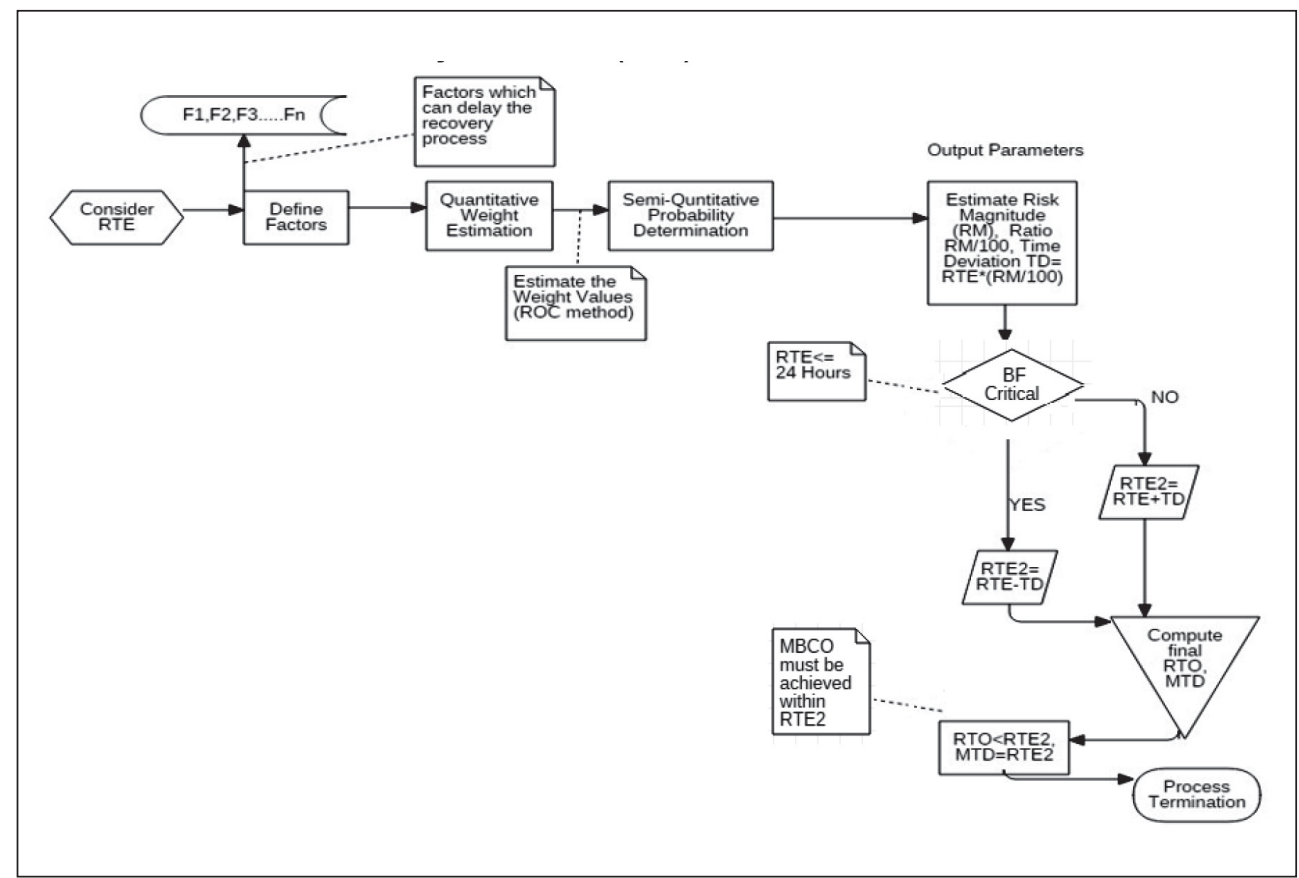




\section{Equations}

According to the proposed by the author algorithmic method, if RTE is the time required to recover a business function in ideal conditions, a non-ideal recovery scenario should be considered for estimating the recovery time as follows:

$$
R T E 2=R T E+\left|R T E \frac{R M}{100}\right|,
$$

and TimeDeviation $=R T E \frac{R M}{100}$

where RTE2 is the new Recovery Time which is based on the assumption that multiple unexpected factors influence the recovery procedure and trigger its significant delay. The Risk Magnitude (Eq. 1) and the Weight Values for all the involved unexpected factors are calculated with the Rank Order Centroid method (Eq. 2).

The final step is to evaluate whether the calculated RTE2 is a satisfactory timeframe to be considered for the recovered business function or system. One secure way to implement the specific task is to measure the availability of the given system by replacing the MTTR with RTE2 in (Eq. 3). The derived equation is the following:

$$
A=\frac{M T B F}{M T B F+R T E 2}
$$

\section{Practical Example - Case Study}

For a practical demonstration of the current approach, the following recovery scenario is considered (Tab. 4).
We assume an information system outage in a greenhouse (i.e. greenhouse irrigation system: "a chemical injection system shutdown while the irrigation pump continues to operate, possibly causing water to backflow through the chemical supply tank and overflow chemical on the ground" (University of Nebraska, 2016)).

Its maximum recovery time after a business continuity exercise has been estimated 2 Hours, which indicates the criticality of the specific business function. The specific timeframe indicates that $\mathrm{RTO}<=2 \mathrm{Hours}$ and MTD $=2$ Hours in order to ensure minor negative environmental impact.

However, during the recovery exercises, no severe conditions triggered by environmental hazards had been considered. We, thus, consider the following 4 unexpected factors which can significantly delay the recovery procedure:

If RTE $=2$ Hours, Number of Factors $(\mathrm{N})=4, \mathrm{WF} 1=0.521, \mathrm{WF} 2=0.271$, WF3 $=0.146$, WF4 $=0.062$ and we assume that semi-quantitatively defined probability of occurrence for each factor are PF1 $=2, P F 2=5$, $\mathrm{PF} 3=2$, PF4 $=4$ then:

$$
\begin{aligned}
& R T E 2=2 \pm 2 \frac{R M}{100}=2 \pm 0.59= \\
& =2.59 \text { Hours or } 1.41 \text { Hours }
\end{aligned}
$$

It should be noticed that the RM values are normalized by multiplying the weight values of each factor with 10 for obtaining more rational results $(w 1+w 2+w 3+w 4=10)$.

\section{Tab. 4: The semi-quantitative probability rating for unexpected factors}

\begin{tabular}{l|c|c|c|c}
$\begin{array}{c}\text { Considered } \\
\text { Unexpected Factors }\end{array}$ & $\begin{array}{c}\text { Impact (Weight } \\
\text { Value) based on } \\
\text { ROC Method }\end{array}$ & $\begin{array}{c}\text { Probability } \\
\text { of Occurrence } \\
\text { (based on a 1-5 Scale) }\end{array}$ & RM/100 & $\begin{array}{c}\text { RTE2 (BF is critical, } \\
\text { because RTE=2Hours, } \\
\text { (RTE<24Hours) }\end{array}$ \\
\hline F1 (Flood) & 5.2 & 2 & & \\
\hline $\begin{array}{l}\text { F2 (Severe Weather } \\
\text { Conditions) }\end{array}$ & 2.7 & 5 & & \\
\hline F3 (Network Failure) & 1.5 & 2 & & \\
\hline F4 (Staff Unavailability) & 0.6 & 4 & $\mathbf{0 . 2 9}$ & $\mathbf{1 . 4 1 \text { Hours }}$ \\
\hline & & & & \\
\hline
\end{tabular}


According to the above calculated values as well as the proposed algorithm, the Maximum Tolerable Downtime (MTD) should be equal to 1.41 Hours. According to our algorithm, for a critical BF as the one included in our example, the value of the TIME Deviation $(T D=2 *(R M / 100))$ should have a negative sign. In this case the risk management policy leads to the consideration of a lower RTE2 value from the initial RTE (RTE2 < RTE), since the latter had been estimated under ideal conditions during the recovery tests.

\subsection{Final Validation via the Availability Formula}

Since the proposed algorithm is aimed for measuring the time required to recover an individual computer based business function, the specific timeframe can be compared with the proposed by domain experts availability of the system that supports the given function. Based on the proposed irrigation time intervals the proposed risk assessment algorithm can be validated by replacing the MTTR with the RTE2. The calculations are implemented as follows:

$$
\begin{aligned}
A_{W} & =\frac{M T B F_{1}}{M T B F_{1}+R T E 2}, \text { and } \\
A_{S} & =\frac{M T B F_{2}}{M T B F_{2}+R T E 2}
\end{aligned}
$$

where $A_{w}$ is the irrigation system availability during the winter period, $A_{S}$ is the irrigation system availability during the spring period, and $M_{T B F_{1}}, M_{T B F_{2}}$ are the corresponding Mean Time Between Failure calculated values (Tab. 3).

By applying the above mentioned formulas (Eq. (7) and Eq. (8)) to the specific irrigation treatments, the following results should be

\begin{tabular}{|c|c|c|}
\hline \multirow[t]{2}{*}{ Tab. 5: } & \multicolumn{2}{|c|}{$\begin{array}{l}\text { Validation of the algorithm with the system availability formula via the irrigation } \\
\text { treatment case study }\end{array}$} \\
\hline & Winter Irrigation Period & Spring Irrigation Period \\
\hline \multicolumn{2}{|c|}{$\begin{array}{l}\text { Achieved System Availability (if MTTR1 = 1.41h): } \\
\mathbf{9 9 . 2 2 \%}\end{array}$} & $\begin{array}{l}\text { Achieved Availability (if MTTR2 }=1.41 \mathrm{~h} \text { ): } \\
\mathbf{9 9 . 4 9 \%}\end{array}$ \\
\hline
\end{tabular}
obtained (Tab. 5):

Source: own

Thus, it can be concluded that the estimated RTE2 value can be effectively used in order to predict the Availability of a critical agricultural processes information system, such as the irrigation system, even when unexpected factors may negatively influence and delay the recovery procedure.

\section{Discussion}

When novel contributions are developed and proposed for specific domains, various issues regarding their value should be considered. Firstly, a contribution should rely on scientifically valid and globally accepted methods and tools. Secondly, the method's novelty, differentiation from similar proposed approaches, practicality and necessity within a specific domain should be justified. Thirdly, when the method is developed scientific issues like the model's consistency and the validity of the obtained results should be demonstrated. Finally, when practical explanatory examples and case studies that include real data are incorporated (i.e. data proposed throughout past experiments), the value of the proposed algorithm becomes more evident. Thus, the selection of the appropriate case study is crucial for the evaluation of the newly introduced contribution.

The currently proposed algorithm is based on all the above mentioned criteria. At first, the contribution is based on mathematical formulas which are utilized for the quantitative and semi-quantitative risk management. The main input parameters in the proposed model parameters are factors which can trigger information system outages in industrial (Torabi, 2016; Maboudian \& Rezaie, 2017) as well as the agricultural systems (Contreras et al., 2017) (i.e. environmental hazards, technical threats, human threats). Especially, though not exclusively, in the case of agricultural systems such factors can delay their recovery procedure and cause significant damage to the environment. Moreover, the method's 
practicality is demonstrated via the utilization of simple equations used for estimating the new recovery time for interrupted business functions.

The novelty of the method is based on the study of the available literature. Even if multiple studies focus on environmental risk management and business continuity, like business continuity in agriculture (Hajek \& Urbancova, 2013) and environment (Madoubian \& Rezaie, 2017), risk management for business continuity (Torabi, 2016), no method combines all disciplines in order to suggest a procedure for estimating the extended recovery time of an individual business function (not groups of business functions (Torabi, 2014)) based on the magnitude of factors which can affect and delay its recovery. However, through the available literature it is highlighted that risk analysis, regarding the recovery of business functions, is a step after the estimation of their recovery time from experts during the Business Impact Analysis (BIA) process (Torabi, 2016). This sequence is followed by the proposed contribution. The definition of the initial recovery time (RTE) is a task that occurs during recovery exercises and is directly linked to the Business Impact Analysis process.

Scientific issues of the method are mainly related to the reliability of the initial RTE sources, and the negative sign of the time deviation. The reliability of the initial RTE sources is ensured based on the recovery time aspect of domain and business continuity experts. The negative sign of the Time Deviation from the initial RTE, has a meaning that a lower time should be afforded when a business function is critical (RTE $<=24$ Hours). Moreover, In order to adjust the RTE2 values to the needs of the currently developed model, the weight values are normalized on a 0 to 10 scale. As a consequence, the Maximum value of RM should be equal to 50 , since the maximum value of Weight is 10 and maximum probability is 5 . As a result, the above mentioned 1-5 scale for the Probability of Occurrence, along with the ROC approach for the weight assignment of the specified factors, prohibits negative or zero values regarding the RTE2 (Eq. 4). Simultaneously, a maximum extended time is proposed, and that is the double time from the initially estimated $\left(\right.$ RTE2 $\left.{ }_{\text {MAX }}=2 R T E\right)$. The practical example utilized includes unexpected factors as above analyzed. Furthermore, the validity of the obtained results is ensured by applying the RTE2 value to the formula which estimates the availability of the business function/information system. For highly critical activities an availability rate $99 \%$ should be achieved, otherwise the recovery policy for the specific business function must be reconsidered.

Finally, a practical example which describes a scenario of an irrigation system interruption is utilized as an approach to evaluating the proposed algorithm. The specific example was selected due to the fact that irrigation system controls water consumption and management which is an environmentally crucial activity. In agriculture, technological problems are highly involved in the adoption of a sustainable water management (Chartzoulakis \& Bertaki, 2015). Thus, from every aspect, the adoption of risk management policies for predicting possible extended failover of irrigation systems is remarkably valuable.

Due to the multiple negative environmental effects caused by a possible irrigation system failover, high availability (more than 99\%) of the specific system is required. A challenging issue is the determination of a policy when predicting lower availability for such systems. In such cases, a reengineering during the business continuity tests can improve the performance of the algorithm and increase the percentage of its predictability. One solution is to consider longer MTBF time intervals or to decrease the number of permitted system failures during a given period when executing the recovery tests.

\section{Conclusions}

The interruption of any information system may result to significant financial, operational and environmental losses. Especially in agriculture interruption of information systems can have a dramatic impact on the environment. Moreover, apart from the environmental damage, such interruptions can be proved economically harmful since they may negatively affect critical agricultural business tasks like vegetable production and distribution based on internet and mobile technologies (Ahrary \& Ludena, 2015).

The currently presented algorithmic approach can achieve an approximate and realistic risk assessment of extended information system interruption as well as a subsequent calculation of the specific time 
deviation from a primarily defined by business continuity experts resumption timeframes (RTO, MTD). The main advantages of the approach are firstly, the mathematical risk assessment based on the risk magnitude formula, the nonarbitrary quantitative definition of the weights of unexpected factors which can trigger time deviation, which relies on the Rank Order Centroid method, and the validation of the new recovery timeframes via the information system availability formula. The idea behind the validation process is the replacement of the Mean Time To Repair (MTTR) value with new recovery time (RTE2) value. The specific action when applied to the greenhouse irrigation system which required availability greater than $99 \%$, demonstrated that the predicted RTE2 ensured $99.22 \%$ system availability during the winter period irrigations, and $99.49 \%$ availability for the spring period.

The currently proposed interdisciplinary algorithmic model can be applied to multiple domains. However, its value to the agricultural field is remarkable since it can be utilized by domain experts in order to reduce the risk of environmental damages caused by such interrupted information systems in agricultural business as the water management systems.

The future work which will complete the current research is the termination of a software solution which will support the currently delineated algorithm. A draft version of a Visual Basic for Applications (VBA) Excel interface has been terminated. The already developed part includes the risk assessment procedure. The currently ongoing work aims to support the validation task via an additional functionality to the specific VBA tool. The VBA excel platform has been selected due to the fact that simple user interfaces for non-expert users can be developed with the specific Microsoft package. Moreover VBA Excel tools are widely used within the agricultural domain (Wang \& $\mathrm{Hu}, 2012$ ), even when modern technologies i.e. cloud and mobile tools are incorporated (Ahrary \& Ludena, 2015). An additional future research target is the application of the current algorithm in mathematical models that measure the concentration of pollutants over time, as is the Air Quality Index (Plaia \& Ruggieri, 2011).

\section{References}

Ahrary, A., \& Ludena, D. A. R. (2015). A Cloud-Based Vegetable Production and
Distribution System. In R. Neves-Silva et al. (Eds.), Intelligent Decision Tecnologies (KES-IDT 2015). Smart Innovation, Systems and Technologies 39 (pp. 11-20). Switzerland: Springer International Publishing.

Aukidy, M. A., Verlicchi, P., \& Voulvoulis, N. (2014). A Framework for the Assessment of the Environmental Risk Posed by Pharmaceuticals Originating from Hospital Effluents. Science of the Total Environment, 493, 54-64. doi:10.1016/j.scitotenv.2014.05.128.

Barron, F. H., \& Barrett, B. E. (1996). Decision Quality Using Ranked Attribute Weights. Management Science, 42(11), 1515-1523. doi:10.1287/mnsc.42.11.1515.

Borghesi, A., \& Gaudenzi, B. (Eds.). (2013). Risk Management, Perspectives in Business Culture. Italia: Springer - Verlag.

Breuer, C., Haasis, H. D., Siestrup, G. (2015). Operational Risk Response for Business Continuity in Logistics Agglomerations. In J. Dethloff, H. D. Haasis, H. Kopfer, H. Kotzab, \& J. Schönberger (Eds.), Logistics Management. Lecture Notes in Logistics (pp. 107-120). Switzerland: Springer International Publishing.

Burns, W. J., \& Slovic, P. (2012). Risk Perception and Behaviors: anticipating and responding to crises. RiskAnalysis, 32(4), 579-582. doi:10.1111/j.1539-6924.2012.01791.x.

Chartzoulakis, K., \& Bertaki, M. (2015). Sustainable Water Management in Agriculture under Climate Change. Agriculture and Agricultural Science Procedia, 4, 88-98. doi:10.1016/j.aaspro.2015.03.011.

Contreras, J. I., Alonso, F., Cánovas, G., \& Baeza, R. (2017). Irrigation management of greenhouse zucchini with different soilmatric potential level. Agronomic and environmental effects. Agricultural Water Management, 183, 26-34. doi:10.1016/j.agwat.2016.09.025.

Danielson, M., Ekenberg, L., \& Sygel, K. (2015). Robust Psychiatric Decision Support Using Surrogate Numbers. Communications in Computer and Information Science, 532, 575-585. doi:10.1007/978-3-319-22689-7 44.

Faertes, D. (2015). Reliability of Supply Chains and Business Continuity Management. Procedia Computer Science, 55, 1400-1409. doi:10.1016/j.procs.2015.07.130.

FAO. (2009). Semi-quantitative risk characterization. Risk Characterization of Microbiological Hazards in food. Retrieved April 20, 2017, from http://www.fao.org/docrep/012/ i1134e/i1134e04.pdf. 
García, I. E. M., Sánchez, A. S., \& Barbati, S. (2016). Reliability and Preventive Maintenance. In W. Ostachowicz et al. (Eds.), MARE-WINT. New Materials and Reliability in Offshore Wind Turbine Technology (pp. 235-272). Switzerland: Springer International Publishing AG.

Hájek, P., \& Urbancová, H. (2013). Using of Business Continuity Standards in Agriculture, Industry and ICT. Agris Online Papers in Economics and Informatics, 5(4), 55-67.

Herbane, B. (2010). The Evolution of Business Continuity Management: A Historical Review of Practices and Drivers. Business History, 52(6), 978-1002. doi:10.1080/0007679 1.2010 .511185 .

ISO. (2012). ISO 22301-2012: Societal Security - Business Continuity Management Systems - Requirements. Retrieved March 25, 2017, from https://www.iso.org/obp/ ui/\#iso:std:iso:22301:ed-1:v2:en.

Jankelova, N., Masar, D., \& Moricova, S. (2017). Risk Factors in the Agriculture Sector. Agricultural Economics, 63(6), 247-258. doi:10.17221/212/2016-AGRICECON.

Maboudian, Y., \& Rezaie, K. (2017). Applying Data Mining to Investigate Business Continuity in Petrochemical Companies. Energy Sources, Part B: Economics, Planning, and Policy, 12(2), 126-131. doi:10.1080/15567 249.2015.1076907.

Malachová, H., \& Oulehlová, A. (2016). Application of Business Continuity Management System in The Crisis Management Field. Transactions of the VŠB - Technical university of Ostrava, Safety Engineering Series, 6(2), 43-50. doi:10.1515/tvsbses-2016-0016.

NIST. (2010). Contingency Planning Guide for Federal Information Systems. Retrieved April 20, 2017, from http://nvlpubs.nist.gov/ nistpubs/Legacy/SP/nistspecialpublication80034r1.pdf.

OECD. (2011). Risk Management in Agriculture: What Role for Governments? Retrieved April 20, 2017, from https://www.oecd. org/agriculture/agricultural-policies/49003833.pdf.

Okuda, K., Ohashi, M., \& Hori, M. (2011). On the Studies of the Disaster Recovery and the Business Continuity Planning for the Private
Sector Caused by Great East Japan Earthquake. Communications in Computer and Information Science, 219. 14-21. doi:10.1007/978-3-64224358-5 2.

Plaia, A., \& Rugierri, M. (2011). Air Quality Indices - A Review. Reviews in Environmental Science and Bio/Technology, 10(2), 165-179. doi:10.1007/s11157-010-9227-2.

Stulec, I., Petljak, K., \& Bakovic, T. (2016). Effectiveness of weather derivatives as a hedge against the weather risk in agriculture. Agricultural Economics, 62(8), 356-362. doi:10.17221/188/2015-AGRICECON.

Thompson, R. B., Gallardo, M., Valdez, L. C., \& Fernández, M. D. (2007). Using Plant Water Status to Define Threshold Values for Irrigation Management of Vegetable Crops Using Soil Moisture Sensors. Agricultural Water Management, 88, 147-158. doi:10.1016/j. agwat.2006.10.007.

Torabi, S. A., Giahi, R., \& Sahebjamnia, N. (2016). An Enhanced Risk Assessment Framework for Business Continuity Management Systems. Safety Science, 89, 201-218. doi:10.1016/j.ssci.2016.06.015.

Torabi, S. A., Rezaei, H., \& Sahebjamnia, N. (2014). A New Framework for Business Impact Analysis in Business Continuity Management (with a case study). Safety Science, 68, 309323. doi:10.1016/j.ssci.2014.04.017.

University of Nebraska - Extension Institute of Agriculture and Natural Resources and the Nebraska Department of Environmental Quality. (2016). Using Chemigation Safely and Effectively. Retrieved April 26, 2017, from http://water.unl.edu/Chemigation\%20Manual_ Revised\%202016.pdf.

Wang, Y., \& Hu, H. (2012). Hydropower Computation Using Visual Basic for Application Programming. Physics Procedia, 24, 37-43. doi:10.1016/j.phpro.2012.02.007.

Ing. Athanasios Podaras, Ph.D. Technical University of Liberec Faculty of Economics Department of Informatics athanasios.podaras@tul.cz 


\title{
Abstract
}

\section{RISK-BASED CONTROL OF THE NEGATIVE EFFECT OF DISCONTINUED AUTOMATED PROCESSES - A CASE FROM THE AGRICULTURAL DOMAIN}

\author{
Athanasios Podaras
}

The current paper delineates a modern algorithmic procedure for estimating the risk and calculating a realistic duration of interrupted critical computerized business activities, in order to mitigate or prevent their corresponding negative consequences. The contribution is formulated via merging risk management and business continuity concepts. The formulation of an integrated business continuity management policy includes the proactive determination of approximate recovery timeframes for critical business functions. Practically, this estimation is based on recovery tests which are executed under ideal conditions, and unexpected factors which may emerge during a real process interruption and significantly delay its recovery are ignored. Agriculture is a domain where the incorporation of an integrated business continuity management system is a crucial issue. The interruption of agricultural computerized activities can be triggered by and can result to various undesirable environmental phenomena. Thus, especially for agriculture, the consideration of unexpected factors when executing recovery tests is highly demanded. The currently presented algorithm accepts as initial input the estimated recovery time which is based on recovery exercises executed under ideal conditions. Then, a precise number of potential unpredictable hazards (factors) are taken into consideration and the risk magnitude of each threat is semi-quantitatively estimated. The total risk magnitude is utilized to estimate the time deviation from the initially defined recovery time. After the risk analysis process is terminated, a new recovery timeframe is proposed. The time deviation from the initially defined recovery time is calculated in its absolute value. The algorithm is finally validated by applying the calculated extended timeframe to the system availability formula which measures the achieved system availability levels for any information system. The validation of the approach is demonstrated via a practical case study from the agricultural domain, namely the greenhouse irrigation scheduling system interruption scenario.

Key Words: Risk management, business continuity, agriculture, environmental hazards, availability.

JEL Classification: Y80, M150.

DOI: 10.15240/tul/001/2017-4-017 